\title{
Ground-Based Augmentation System Operation in Low Latitudes - Part 2: Space Weather, Ionospheric Behavior and Challenges
}

\author{
Jonas Sousasantos ${ }^{1}$ (D), Leonardo Marini-Pereira2, ${ }^{*}$ (D), Alison de Oliveira Moraes $^{3}$ (D), Sam Pullen $^{4}$ (D)
}

1. Departamento de Ciência e Tecnologia Aeroespacial - Instituto Tecnológico de Aeronáutica - Divisão de Ciência da Computação São José dos Campos/SP - Brazil. 2. Departamento de Controle do Espaço Aéreo - Instituto de Controle do Espaço Aéreo Divisão de Pesquisa - São José dos Campos/SP - Brazil. 3. Departamento de Ciência e Tecnologia Aeroespacial - Instituto de Aeronáutica e Espaço - Divisão de Eletrônica - São José dos Campos/SP - Brazil. 4. Stanford University - Department of Aeronautics and Astronautics - Stanford/CA - United States of America.

*Correspondence author: marinilmp@fab.mil.br

\begin{abstract}
Ionospheric dynamics over low latitudes, especially in Brazil, are highly active, with several phenomena resulting from the complex interaction between space weather and atmospheric elements. These phenomena may cause disruptions to aviation communications, navigation and surveillance systems. Motivated by the issues posed by the ionosphere to the operation of ground-based augmentation of global navigation satellite systems (GNSS) in Brazil, this review paper presents fundamental physical aspects of space weather and low-latitude ionospheric dynamics to show how and why the ionosphere over Brazil is much more challenging for satellite-based positioning technologies. Solar influence, geomagnetic field configurations under quiet and storm periods, and the ensuing ionospheric dynamics over low latitudes occasionally lead to the development of structures known as equatorial plasma bubbles. These structures can produce strong plasma gradients within the ionosphere and cause scintillation on transionospheric signals. The consequences of these structures for GNSS users are specifically addressed.
\end{abstract}

Keywords: Ionosphere; Low latitudes; Equatorial plasma bubbles; GNSS; GBAS.

\section{INTRODUCTION}

In the first of this two-part series of survey papers, the main aspects of ground-based augmentation system (GBAS) technology and the influence of the ionosphere on its performance were presented, with emphasis on integrity. In addition, efforts towards implementation of GBAS in Brazil and the main findings regarding the ionospheric threat space were presented and discussed. Since ionospheric effects create major operational and safety-related impacts on GBAS in Brazil, it is vital to describe the most critical mechanisms of low-latitude ionosphere in detail. This paper is devoted to providing an explanation of the low-latitude space weather dynamics that cause such a strong influence on global navigation satellite system (GNSS)-based technologies, like GBAS.

Received: Aug. 17, 2021 | Accepted: Oct. 18, 2021

Peer Review History: Double Blind Peer Review.

Section editor: Luiz Martins-Filho

This is an open access article distributed under the terms of the Creative Commons license. 
In aviation, space weather events in general affect not only air navigation. Besides affecting the performance of GNSS-based systems, several issues with communication and the avionics electronics may occur. Motivated by this concern, the International Civil Aviation Organization (ICAO) has recently published the first edition of Doc 10100 (ICAO 2019) to enable operators to make informed decisions concerning space weather impacts. The document lists the most relevant impacts on civil aviation in terms of potential hazards and recommends space weather indicators to be published by air navigation service providers. It is worth mentioning that in the cited document, ICAO encourages the creation of the so-called space weather centers and states that each civil aviation authority (CAA) is responsible for integrating space weather considerations into existing aviation operations and planning.

As pointed out in ICAO (2019), a detailed understanding of space weather phenomenology and ionospheric dynamics may not directly benefit operators within or contracted by a CAA, since it is outside their normal area of expertise. However, it is expected that specialists who support operators and decision makers will have a more complete knowledge of space weather phenomena based on publications such as this one.

The term "space weather" is typically employed to refer to a set of phenomena caused by the Sun-Earth interaction. Depending on the theme to be explored, the contribution from external sources, such as cosmic rays, may also be referred to as a space weather phenomenon. However, the Sun is the primary driver of nearly all space weather phenomena affecting the Earth. The solar influence over the Earth is regulated by Earth's magnetic field (geomagnetic field). Solar radiation and Earth's geomagnetic field generate a set of currents and electric fields that are formed in a region mostly located from 50-1000 km of altitude that is named the ionosphere. The interaction between these elements is very complex and depends upon a large number of variables, some of which are key to GNSS impacts and are discussed in more detail throughout this paper.

In the second section of this paper, basic information about the solar influence on ionospheric environment formation is presented. The third section is devoted to introducing the geomagnetic field configuration and its interaction with solar elements, such as solar wind, coronal mass ejections (CMEs), and solar flares. Idiosyncrasies within the Brazilian region are also discussed. The fourth section presents low-latitude ionospheric morphology and phenomenology. The discussion includes plasma drift, the fountain effect and the equatorial ionization anomaly (EIA), the pre-reversal enhancement of the electric field, equatorial plasma bubbles (EPBs) and subsequent events such as ionospheric scintillation and enhanced plasma gradients. The fourth section also introduces examples of the impact of plasma bubbles on GNSS applications and GBAS systems, demonstrating that interactions between the space weather elements must be considered for any application performed in low-latitude environment. The last section presents the final remarks of this paper.

\section{THE SOLAR INFLUENCE ON SPACE WEATHER}

As mentioned earlier, the Sun is the primary driver for most space weather phenomena affecting the Earth. Solar radiation is responsible for ionizing atoms and molecules in Earth's atmosphere, generating the region known as the ionosphere. Several wavelengths contribute to this ionization by being absorbed when penetrating the atmosphere. Extreme ultraviolet (EUV) wavelengths in the range $170 \leq \lambda \leq 911 \AA\left(1 \AA=1\right.$ angstrom $\left.=1 \times 10^{-10} \mathrm{~m}\right)$ are mainly absorbed in the upper portion of the atmosphere (i.e., altitudes higher than $150 \mathrm{~km}$ ), while EUV with wavelengths of $911<\lambda \leq 1027 \AA$ ionizes the atmosphere around $80-150 \mathrm{~km}$ of altitude. At these altitudes, $\mathrm{x}$-rays with $10<\lambda \leq 170 \AA$ also play an essential role in the ionization process, together with Lyman- $\beta(\lambda=1026 \AA)$ radiation. The lower portion of the atmosphere with substantial ionization is located around $50-80 \mathrm{~km}$ of altitude. This ionization is mainly produced by the influence of Lyman- $\alpha(\lambda=1216 \AA)$ and $\mathrm{x}$-rays $(1 \leq \lambda \leq 10 \AA)$ radiation (Rishbeth and Garriott 1969$)$.

Solar energy is also responsible for causing temperature gradients that drive winds in the upper atmosphere. The particles transported in this flow have distinct motions according to their cross-sections, collision frequencies, and other parameters. As a result, positively/negatively charged particle (ion/electron) movements establish electric fields and currents depending on the conductivity of the ambient environment (Prölss 2011). 
Besides radiation, the Sun expels a continuous stream of solar material towards the interplanetary medium. This flux of plasma of solar nature is named "solar wind" (Parker 1958). Aside from this flux of material, large bursts of radiation and solar material occur sporadically. These eruptions are known as solar flares and coronal mass ejections, respectively. These extreme solar events are usually classified according to the $\mathrm{x}$-ray $(1 \leq \lambda \leq 10 \AA)$ peak flux, in $\mathrm{W} \cdot \mathrm{m}^{-2}$, following an increasing sequence of letters $\mathrm{A}$, $\mathrm{B}, \mathrm{C}, \mathrm{M}$, and $\mathrm{X}$ associated with a number between 0 and 9 . An event of class $\mathrm{M}$ (or larger) is capable of triggering considerable terrestrial impacts and radio blackouts (Knecht and Davies 1961; Tsurutani et al. 2009).

Due to the influence of these solar features, an intrinsic relationship between solar activity and Earth's environment is believed to exist (Abdu et al. 1985; Sahai et al. 1999). Therefore, solar activity is usually inspected by evaluating the number of sunspots as a measure of the intensity of solar activity. For more general purposes, an index named F10.7 is often employed. The F10.7 index measures the solar flux at a wavelength of $10.7 \mathrm{~cm}$ at a distance from the Sun corresponding approximately to Earth's orbit. Its units, referred to as solar flux units (s.f.u.), are given in terms of $10^{-22} \mathrm{~W} \cdot \mathrm{m}^{-2} \cdot \mathrm{Hz}^{-1}$, and its values are highly correlated with the sunspot number. An example of solar flux measurements and their relationship with the sunspot number is shown in Fig. 1.
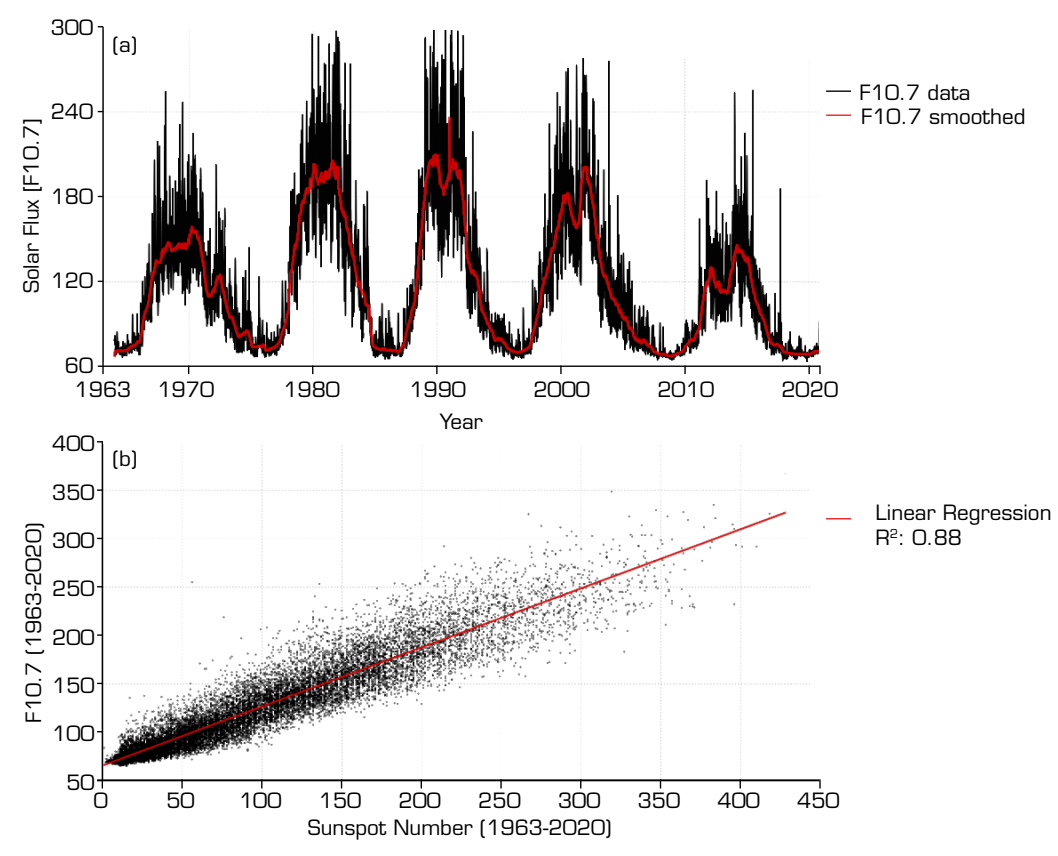

Source: Elaborated by the authors using data from NASA (2004).

Figure 1. Solar flux records along five decades. (a) Solar flux described by the F10.7 index along the years 1963-2020 (available dataset); (b) Sunspot number, F10.7, and the relationship between these quantities during 1963-2020.

The dataset presented in the panels of Fig. 1 covers the years 1963-2020 and may be accessed at the website available at NASA (2004). Figure 1a shows the F10.7 index data (solid black line) and a smoothed version of this index (solid red line) over this period. A cyclic pattern is clearly visible. This pattern repeats approximately every 11 years and is often referred to as the solar cycle. Note that the peak of solar activity (i.e., the F10.7 peak) varies considerably from one cycle to another.

In Fig. 1b, a comparison between the sunspot number and the F10.7 index is shown. A nearly linear relationship between these quantities $\left(\mathrm{R}^{2}=0.88\right)$ is observed. This is one of the reasons why, for most practical applications, the F10.7 index is used without loss of generality. For instance, global positioning system (GPS) single-frequency users depend on this quantity because the coefficients in the GPS message are generated based on the F10.7 index value (Feess and Stephens 1987; Klobuchar 1987). Hence, any scientific study about the Earth space environment or technological application based on satellite communication must consider solar flux behavior in its analysis. 


\section{THE GEOMAGNETIC FIELD AND GEOMAGNETIC STORMS}

As mentioned earlier, the solar wind continuously flows towards Earth, whose geomagnetic field lines surrounding the planet act as a natural shield. This external envelope of geomagnetic field lines is known as the magnetosphere. The solar wind is a fully ionized plasma and, when reaching the magnetosphere, its particles are deflected according to their charges, creating an electrical current surrounding the Earth (Parker 1957a). The solar wind plasma also carries "frozen-in" magnetic fields, and, depending on the direction of this interplanetary magnetic field, a phenomenon known as magnetic reconnection may happen (Alfvén 1958; Parker 1957b). When reconnection happens, solar material penetrates through some of the geomagnetic field lines, and these particles drift along the inner field lines according to their respective pitch angles, eventually reaching the poles, heating the region and causing auroras. This situation may alter the electrodynamics of the low-latitude ionosphere in at least two distinct ways: (1) introducing a prompt penetration electric field, and (2) changing the winds (and electric fields due to the dynamo effect) after few hours as a result of Joule heating (current increase) at the poles.

A pictorial representation of this situation is presented in the panels of Fig. 2. The components of the geomagnetic field lines (solid black lines) around the equator are approximately directed northward, as indicated by the arrows ( $\left.\mathbf{B}_{E}\right)$. In Fig. $2 \mathrm{a}$, the solar wind velocity component $\left(\mathbf{V}_{S W}\right)$ directed towards the Earth, the interplanetary magnetic field $\left(\mathbf{B}_{S W}\right)$ is directed northward, and the electric field is generated by these two quantities $\left(\mathbf{E}_{S W}=-\mathbf{V}_{S W} \times \mathbf{B}_{S W}\right)$ is directed westward (as seen from Earth). The direction of $\mathbf{B}_{S W}$ is parallel to $\mathbf{B}_{E}$, and there is no reconnection on the dayside. The solar wind compresses the Magnetosphere on its sunward side and stretches the opposite side, imposing a form similar to a tail.

(a)
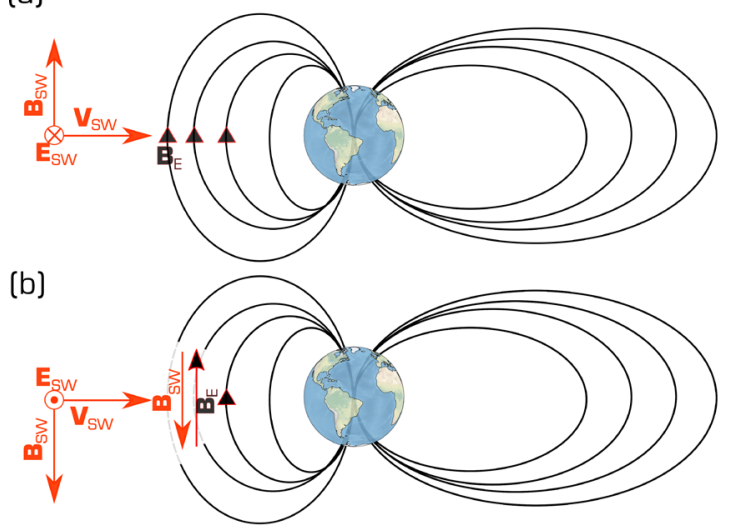

[c]

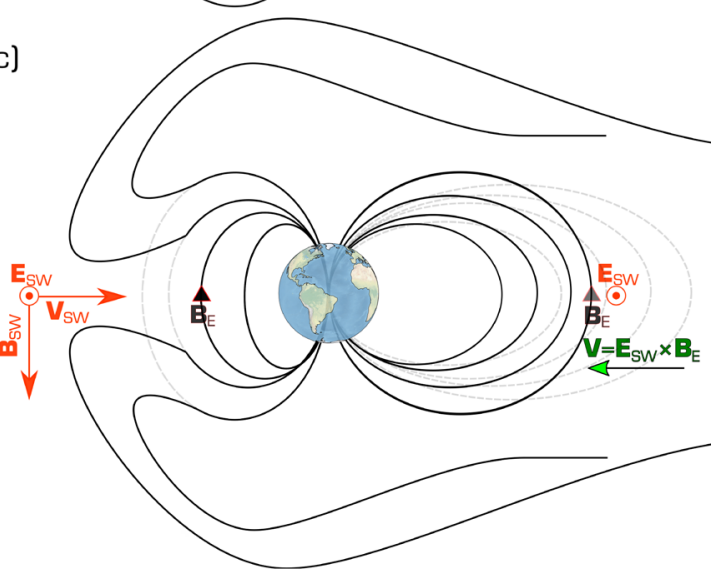

Source: Elaborated by the authors.

Figure 2. Pictorial representation of the magnetic reconnection process. (a) Ordinary magnetospheric configuration under a northward $\mathbf{B}_{S W}$; (b) Magnetic reconnection development process under southward $\mathbf{B}_{S W}$; (c) Later stage of the magnetic reconnection depicting the closure of the field lines in the opposite side (tail) of the magnetosphere. 
Figure $2 \mathrm{~b}$ depicts a different situation with $\mathbf{B}_{S W}$ directed southward (hence, $\mathbf{E}_{S W}$ is directed eastward). In this case, $\mathbf{B}_{S W}$ and $\mathbf{B}_{E}$ have opposite orientations, and a process between the magnetic fields occurs, causing an effect analogous to opening the geomagnetic field lines.

Figure $2 c$ depicts a later stage of magnetic reconnection when the geomagnetic field lines reconnect in the other side (tail) of the magnetosphere. During these events, $\mathbf{E}_{S W}$ causes convection of the magnetospheric tail in the sunward direction $\left(\mathbf{V}=\mathbf{E}_{S W} \times \mathbf{B}_{E}\right)$, giving rise to the so-called "Region 2" currents near the equatorial plane in the ionosphere and creating a partial dusk-to-dawn electric field that tends to shield the near-Earth region opposing the convection in the inner magnetosphere. These shielding electric fields immediately alter the electrodynamics over low-latitude regions significantly (Abdu et al. 2009a; 2012; 2016; Fejer et al. 2021; Kelley et al. 1979a; Kikuchi et al. 2008; Peymirat et al. 2000). This aspect must be considered every time a space weather evaluation is carried out but may be taken into account indirectly through other parameters to be discussed later.

The second consequence brought by these events is auroral heating, creating winds moving equatorward. Because of the Earth rotation, these winds acquire a westward component changing the electrodynamics over low latitudes. This condition is commonly referred to as a disturbance dynamo. It typically occurs a few hours after the magnetic reconnection set up and has long-lasting effects (Blanc and Richmond 1980). When the Earth's environment is under such conditions, it is said that a geomagnetic storm (or substorm) is underway. Geomagnetic storms are more likely to occur during extreme solar events, such as coronal mass ejections, while solar wind changes primarily drive substorms (brief geomagnetic disturbances mainly caused by sudden changes in the magnetotail region).

For practical purposes, several geomagnetic indexes have been proposed to quantify a geomagnetic storm disturbance. The most widely used and of most interest for the present discussion are the disturbance storm-time (Dst) index (Sugiura 1964; Sugiura and Kamei 1991) and the planetary K (Kennziffer) (Kp) index (Bartels 1938; Bartels et al. 1939). The Dst index measures the magnetic signature of magnetosphere currents (ring, tail and Chapman-Ferraro currents) that usually cause a steep decrease in the horizontal component of the geomagnetic field during the disturbed period. The geomagnetic storm level, according to the Dst index, may be classified as weak (Dst $\leq-30 \mathrm{nT}$ ), moderate (Dst $\leq-50 \mathrm{nT}$ ), strong (Dst $\leq-100 \mathrm{nT})$, severe (Dst $\leq-200 \mathrm{nT})$ and exceptional (Dst $\leq-350$ nT) (Loewe and Prölss 1997).

The Kp index measures the disturbances in the horizontal component of the magnetic field based on information from midlatitude stations and has been calculated since 1932. The geomagnetic activity, in terms of Kp index, may be classified as quiet $(\mathrm{Kp}<4)$, active $(\mathrm{Kp}=4)$, minor storm $(\mathrm{Kp}=5)$, and major to severe storm $(\mathrm{Kp}>5)$ (Tan et al. 2018). Another index worth mentioning is the auroral electrojet (AE) index (Davis et al. 1966), primarily used to evaluate substorm processes, but its usage is beyond the scope of the present discussion.

An example of a geomagnetic storm measured through Dst (solid black line) and Kp (red bars) indexes is presented in Fig. 3. The dataset used in this figure covers October 27, 2003 to November 3, 2003 and can be accessed at the website available at NASA (2004).

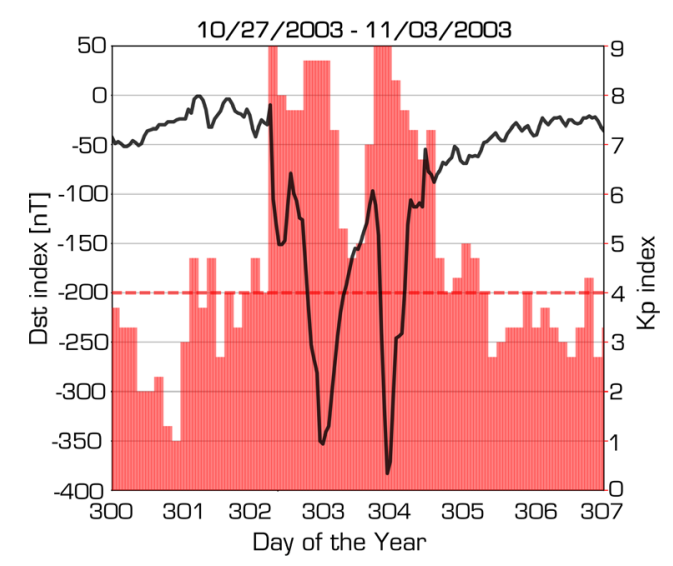

Source: Elaborated by the authors using data from NASA (2004).

Figure 3. Geomagnetic storm measured by the Dst (solid black line) and Kp (red bars) indexes. The red dashed line indicates the Kp threshold level above which the geomagnetic activity begins. 
On day of year 301 (October 28, 2003), small fluctuations in the Dst and Kp values larger than 4 suggest a minor storm, but after day 302 (October 29, 2003), the geomagnetic indexes revealed a massive geomagnetic storm (Dst $<-350 \mathrm{nT}$ and Kp $=9$ ). A very similar storm trend may be verified by comparing the two indexes. Furthermore, this event caused strong responses over low-latitude regions (Abdu et al. 2007), and this is generally the case (Abdu et al. 2012). Therefore, any user of systems depending on satellite communication should keep track of these two indices.

Besides these events, the configuration of the geomagnetic field lines around the planet is also essential to understanding the low-latitude phenomenology. At least two aspects deserve special attention when analyzing the low-latitude ionosphere: the declination component and the geomagnetic field intensity. Declination plays a determining role in wind dynamo electric fields through Lorentz force and the configuration of the circuit closure between the low-latitude and equatorial ionosphere (Abdu et al. 1981; 1992). Geomagnetic field intensity has a region of intense decrease known as the south Atlantic magnetic anomaly (SAMA), which is currently concentrated along the Brazilian/Atlantic coast. In this region, the precipitation of particles is enhanced, and the movement of plasma is different from other locations.

The Brazilian territory has the largest declination and steepest decrease in geomagnetic field intensity among the equatorial region. Therefore, its near-space phenomenology is peculiar, and satellite system applications suffer from a stronger and more diverse scenario.

An example of the current geomagnetic field configuration is presented in the panels of Fig. 4. Figure $4 \mathrm{a}$ and b show the geomagnetic declination and intensity, respectively, according to the International Geomagnetic Reference Field (IGRF), considering an ionospheric reference altitude of $350 \mathrm{~km}$.

On Fig. 4a, one can observe that, considering equatorial (black dashed line) and low-latitude regions, the most pronounced declination is around Brazilian territory (highlighted by the western red dashed line). In addition, Fig. $4 \mathrm{~b}$, which shows the geomagnetic intensity, clearly presents a steep decrease (darker blue region within white dashed contours) around Brazilian territory, characterizing the SAMA. These plots indicate that the ionospheric environment over the Brazilian region is one of the most difficult to predict and hard to handle for satellite-dependent purposes due to its varied and unique features. The IGRF model used to produce the figure may be accessed at the website IAGA (2019).

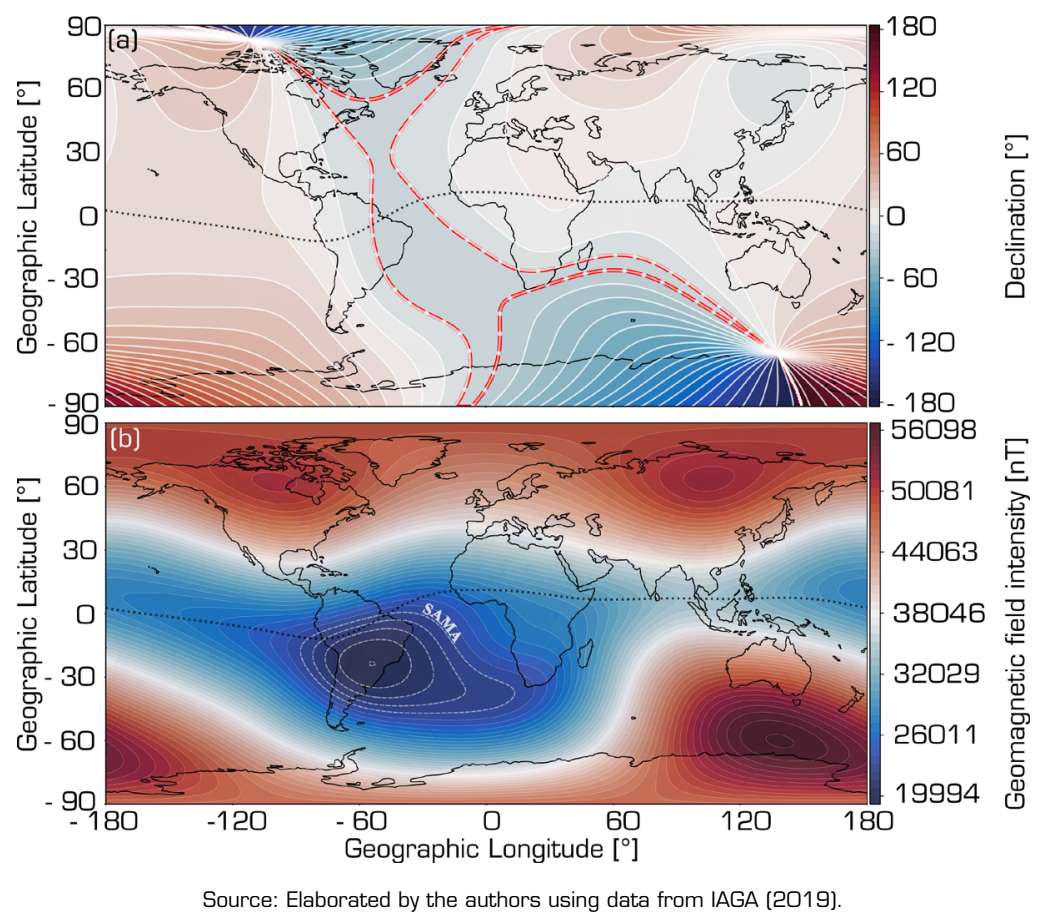

Figure 4. Distribution of the declination and intensity of the geomagnetic field along the globe. (a) Geomagnetic field declination component, the Brazilian territory is the low-latitude region with a more pronounced declination (red dashed lines); (b) Geomagnetic field intensity. The SAMA (white dashed lines) is concentrated in low latitudes across the Brazilian region. In these panels, the black dashed lines correspond to the geomagnetic equator. 
As previously mentioned in this paper, the primary interest of space weather investigations for satellite-based applications is the solar and geomagnetic influences acting over the Earth's plasma environment, called the ionosphere. In the next section, lowlatitude Earth ionosphere phenomenology is discussed in more detail.

\section{IONOSPHERIC MORPHOLOGY AND PHENOMENOLOGY OVER LOW-LATITUDE REGIONS}

Earth's atmosphere has a distribution of neutral elements that tends to exponentially decrease with altitude under the action of gravity following the hydrostatic equation:

$$
-\frac{d\left(N_{n} k_{B} T\right)}{d h}=N_{n} m_{n} g
$$

where $N_{n}, k_{B}, T, m_{n}, g$ and $h$ corresponding to neutral density, Boltzmann constant, neutral temperature, neutral mass, gravity and altitude, respectively. In contrast, the photoionization produced by solar radiation increases significantly with altitude. The conjunction between these two profiles gives rise to a region of weakly ionized plasma between 50 and $1000 \mathrm{~km}$ called the ionosphere.

The ionosphere is often divided into three main regions: $\mathrm{D}, \mathrm{E}$, and $\mathrm{F}$. In the $\mathrm{D}$ region $(\sim 50-85 \mathrm{~km})$, particle momentum is controlled by the neutral atmosphere, hence the geomagnetic field has a secondary role. Let $v_{i, e n}$ be the ion/electron-neutral collision frequency and let $\Omega_{i, e}$ be the ion/electron gyrofrequency, then:

$$
\Omega_{i, e}=\frac{q B}{m_{i, e}}
$$

where $q=$ elementary charge, $B=$ geomagnetic field intensity and $m=$ element mass. The ratio between the ion/electron-neutral collision frequency and the ion/electron gyrofrequency is expressed by:

$$
k_{i, e}=\frac{\Omega_{i, e}}{v_{i, e n}}
$$

In the $\mathrm{D}$ region of the ionosphere, $k_{i, e}<<1$. The neutral atmosphere still controls the ion dynamics in the $\mathrm{E}$ region $(\sim 85-150 \mathrm{~km})$. However, electrons are dominated by the geomagnetic field (i.e., $k_{i}<<1$, but $k_{e}>>1$ ); hence, currents and electric fields are formed depending on the ionospheric ambient conductivity. This change is mainly caused due to the steep decrease of the neutral density. In the F region ( $>150 \mathrm{~km}$ ), the geomagnetic field dominates the dynamics (i.e., $k_{i, e}>>1$ ), and the plasma density reaches its peak. Thus, the low-latitude $\mathrm{E}$ and $\mathrm{F}$ regions and the equatorial $\mathrm{F}$ region are where the phenomenology of interest for satellite-dependent systems is primarily concentrated.

The evaluation of the ionospheric plasma density $(\mathrm{N})$ is commonly done considering the electron density $\left(\mathrm{N}_{e}\right)$ instead of the individual ion densities $\left(\mathrm{N}_{i}\right)$ because of the quasi-neutrality condition $\left(\Sigma_{i} \mathrm{~N}_{i}=\mathrm{N}_{e}=\mathrm{N}\right)$. Figure 5 shows one example of a typical electron density vertical profile over a low-latitude region during a summer season and high solar F10.7, as obtained through the International Reference Ionosphere (IRI) (CCMC 2000) model (Bilitza et al. 2017). The IRI is the official standard model for the ionosphere according to the International Standardization Organization (ISO), the International Union of Radio Science (URSI), the Committee on Space Research (COSPAR), and the European Cooperation for Space Standardization (ECSS), and it is available online at the website CCMC (2000).

In Fig. 5, one can observe that the plasma density varies greatly with altitude and is concentrated in the $\mathrm{E}$ and $\mathrm{F}$ regions. In the upper $\mathrm{D}$ and $\mathrm{E}$ regions, the dominant ions are $\mathrm{NO}^{+}$and $\mathrm{O}_{2}^{+}$, while in the $\mathrm{F}$ region, the plasma is mainly composed of $\mathrm{O}^{+}$and $\mathrm{H}^{+}$ ions (Johnson 1969). Moreover, the momentum dominance, related to the $k_{i, e}$ ratio, also changes considerably. The variation in electron and ion densities, in the ratio $k_{i, e}$, and in the geomagnetic field are directly related to ionospheric conductivity. Therefore, a significant change with altitude is expected. The conductivity tensor $(\tilde{\boldsymbol{\sigma}})$ in the low-latitude region may be expressed as: 


$$
\tilde{\boldsymbol{\sigma}}=\left[\begin{array}{ccc}
\sigma_{P} & \sigma_{H} & 0 \\
-\sigma_{H} & \sigma_{P} & 0 \\
0 & 0 & \sigma_{\|}
\end{array}\right]
$$

where $\sigma_{p}, \sigma_{H}$ and $\sigma_{\|}$are the Pedersen, Hall and parallel components. These components are, respectively, equivalent to those expressed in Eq. 5:

$$
\begin{aligned}
& \sigma_{P}=\frac{N}{q B}\left(\frac{k_{e}}{1+k_{e}^{2}}+\frac{k_{i}}{1+k_{i}^{2}}\right) \\
& \sigma_{H}=\frac{N}{q B}\left(\frac{k_{e}^{2}}{1+k_{e}^{2}}-\frac{k_{i}^{2}}{1+k_{i}^{2}}\right) \\
& \sigma_{\|}=\frac{N}{q B}\left(k_{e}+k_{i}\right)
\end{aligned}
$$

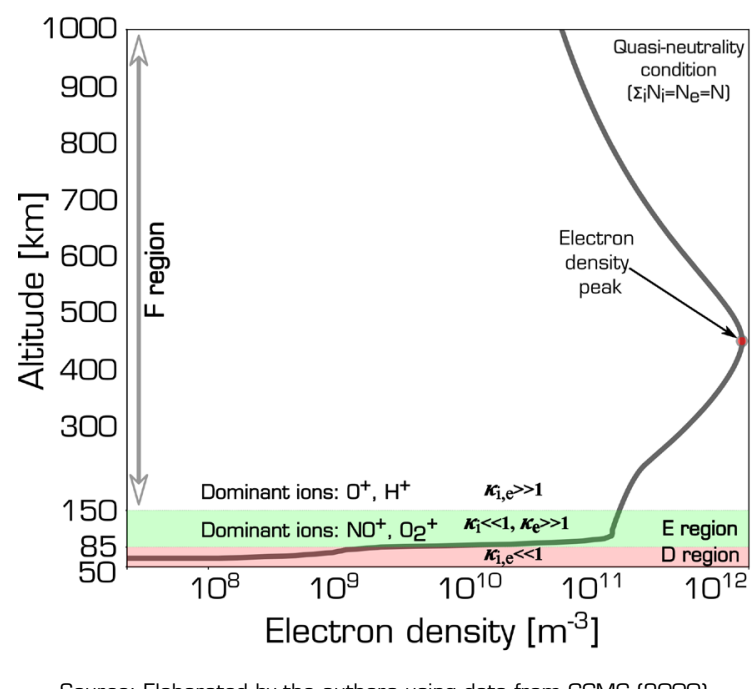

Figure 5. Electron density $\left(\mathrm{N}_{e}\right)$ vertical profile across the D (red shaded area), E (green shaded area) and F regions.

Please notice that the plasma density exhibits a large variation with altitude and is mostly concentrated in the $\mathrm{E}$ and $\mathrm{F}$ regions.

Considering the perpendicular components of the conductivity $\left(\sigma_{p}\right.$ and $\left.\sigma_{H}\right)$, the E region has the largest ionospheric conductivity, being the Hall component the more pronounced due to the larger $k_{e}$. Hence, currents flow more efficiently in this region. In the $\mathrm{F}$ region, the Pedersen component of conductivity dominates, but it is smaller. Therefore, electric fields endure longer in these altitudes.

\section{Plasma drifts, Fountain Effect and the EIA}

Over the equatorial and low-latitude regions, ionospheric phenomenology is rich and has a large variability depending on several parameters presented in the previous equations. During the daytime, the E region controls its electrodynamics. Atmospheric tides (neutral motions generated by temperature gradients and gravity forcings) are responsible for generating electric fields in this region, where the large conductivity establishes a system of currents. Electric fields generated in the daytime equatorial $\mathrm{F}$ region are short-circuited to the low-latitude $\mathrm{E}$ region due to the large parallel conductivity $\left(\sigma_{\|}\right)$along the geomagnetic field lines. After dusk, the photoionization ceases, the chemical recombination consumes the ionization from below, and the $\mathrm{D}$ and $\mathrm{E}$ regions vanish. As a consequence, the $\mathrm{F}$ region controls the electrodynamics while depending on features such as thermospheric winds. It is worth noticing that the most drastic phenomena over the equatorial and low-latitude regions occur after dusk and are, therefore, mainly related to $\mathrm{F}$ region electrodynamics. 
In the case of any force $(\boldsymbol{F})$ acting over a plasma, a velocity component in the following form will occur (Eq. 6).

$$
\boldsymbol{V}=\frac{\boldsymbol{F} \times \boldsymbol{B}}{q B^{2}}
$$

Due to the electric fields $(\boldsymbol{E})$ residing in the F region, the plasma in these altitudes exhibits a velocity given by Eq. 7 , which is usually referred to as plasma drift velocity or electromagnetic plasma drift.

$$
\boldsymbol{V}=\frac{\boldsymbol{E} \times \boldsymbol{B}}{B^{2}}
$$

This expression shows that a zonal/vertical electric field generates a vertical/horizontal component of plasma drift in the equatorial and low-latitude ionosphere. The prevalent zonal (eastward) electric field during the daytime causes an upward plasma drift over the equatorial region. This movement is independent of charge; hence, the plasma bulk is transported collectively. As the plasma drifts upward, it faces opposite forcing from gravity $(\mathbf{g})$ and pressure gradients $(\nabla \mathrm{p})$, and, due to the large parallel conductivity $\left(\sigma_{\|}\right)$, it flows along the field lines to off-equator latitudes. This movement of plasma being elevated over the equator and transported to lower altitudes within the low-latitude region is known as the fountain effect (Anderson 1973; Hanson and Moffet 1966; King 1968). As a result of the fountain effect, the plasma density distribution, which is expected to be larger over the equator (due to the more significant solar incidence), is anomalously concentrated over the low-latitude region. This distribution is known as EIA.

Figure 6 shows one example of the formation of the Equatorial Ionization Anomaly (EIA) due to the fountain effect using the numerical model SAMI2 (Huba et al. 2000). The panels in Fig. 6 exhibit a time sequence of electron density profiles in the latitude/ altitude plane over the Brazilian region. As the solar incidence starts in the early morning (05:00-09:00 LT), photoionization increases the electron density $\left(\mathrm{N}_{e}\right)$. The concentration of $\mathrm{N}_{e}$ is initially over the equatorial region. However, due to the fountain effect, the plasma is redistributed along the geomagnetic field lines and forms two crests over low-latitude regions, as shown in the Fig. 6 a for 13:00 LT. This plasma flow is intensified along the day, reaching its maximum in early nighttime (in the Fig. $6 \mathrm{~d}$ and e for 17:00 and 21:00 LT). Later in the night, due to chemical recombination and decreasing vertical plasma drift, the EIA density decreases substantially, lasting up to a few hours after 00:00 LT.
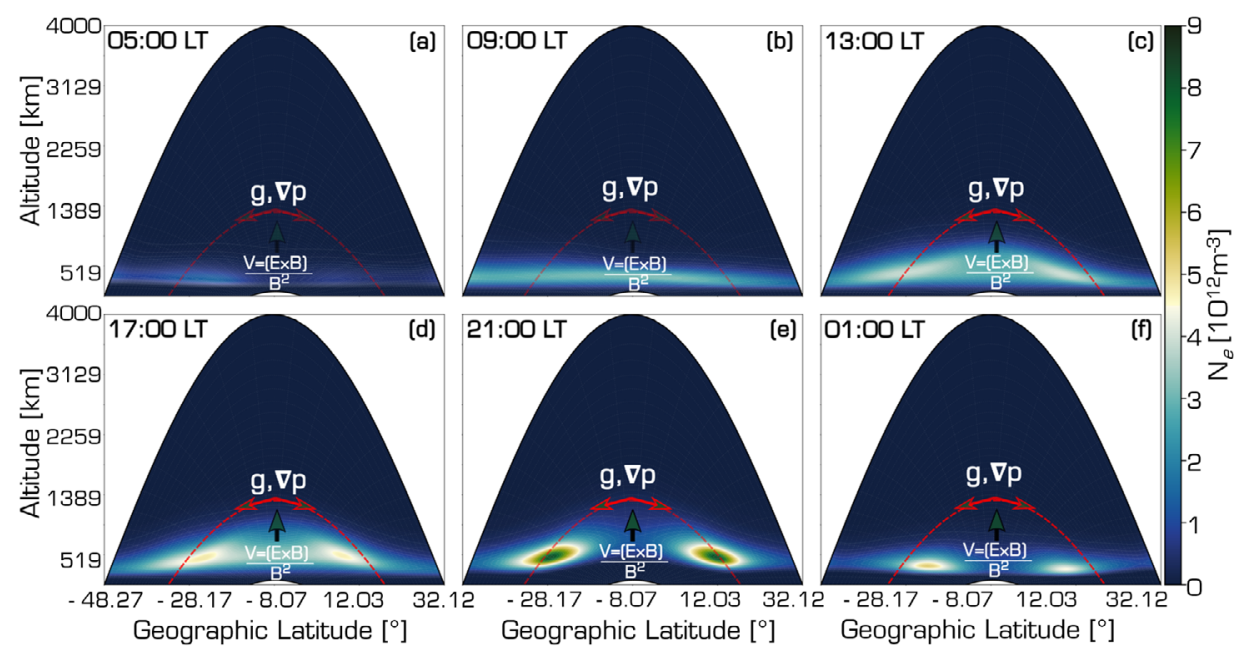

Source: Elaborated by the authors.

Figure 6. Example of the fountain effect and EIA formation obtained through numerical simulation. Along the panels (Fig. 6a-f), one arbitrary line of the geomagnetic field (red dashed line) is highlighted to illustrate the process, and transparency is used as a visual tool corresponding to the intensity of the upward drift over the equator and strength of the EIA. 


\section{Prereversal vertical drift, EPBs and scintillation}

In the dusk region (i.e., twilight zone), a significant ionospheric conductivity gradient is present across the solar terminator. The steep conductivity decrease changes the currents in the E region and, consequently, the electric fields in the equatorial $\mathrm{F}$ region. The thermospheric winds $(\mathbf{W})$ in the equatorial dusk $\mathrm{F}$ region originate a downward electric field $(\mathbf{E}=-\mathbf{W} \times \mathbf{B})$. These equatorial downward $\mathrm{F}$ region electric fields are mapped to the low-latitude $\mathrm{E}$ region. Considering the Ohm's law, $\mathbf{J}=\tilde{\boldsymbol{\sigma}} \cdot \mathbf{E}$ in the E region, this electric field drives a downward Pedersen current and a westward Hall current. However, because of the steep decrease in conductivity, positive/negative charges pile up in the downward/ terminator boundaries due to these currents. The accumulation of charges in the lower limit of the $\mathrm{E}$ region gives rise to an upward electric field that tends to counterbalance the downward electric field mapped from the F region. As a result, the eastward/westward electric field generated in the dayside/nightside of the ionosphere by the westward current and the conductivity gradient across the terminator is mapped back to the equatorial F region. In combination with the northward component of the geomagnetic field, this causes an abrupt upward/downward drift in the dayside/nightside ionosphere. This mechanism was reported in Farley et al. (1986) and is known as prereversal enhancement (PRE) of the electric field or vertical drift (PRVD).

Figure 7 shows the vertical component of the plasma drift over a typical summer day over the Brazilian region during high solar flux and quiet geomagnetic conditions (i.e., not a storm/substorm period) as obtained from the IRI 2016 model. During the daytime (blue shaded area), the chiefly eastward zonal electric field causes dominant upward plasma drift. In the nighttime (red shaded area), the westward zonal electric field has the opposite effect, i.e., it causes a downward plasma drift. In the terminator region (cyan shaded area), a steep increase in the vertical drift is clearly evident.

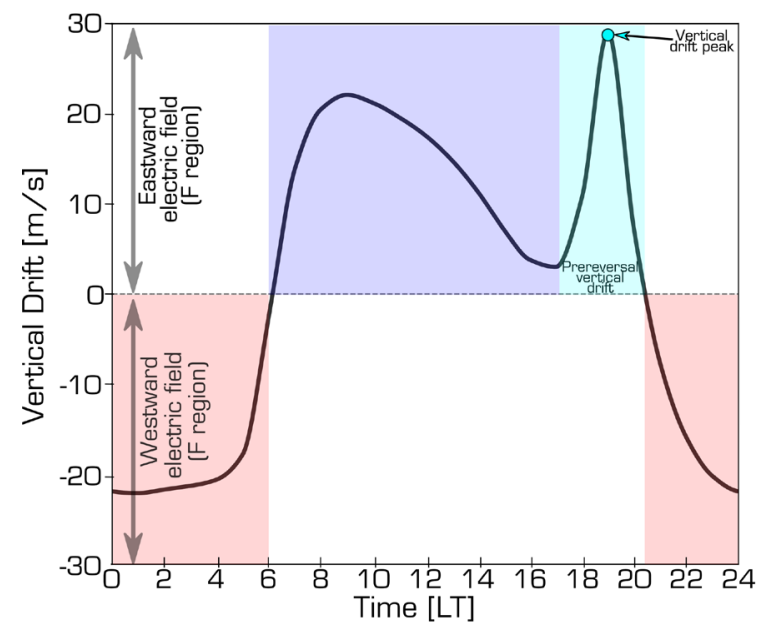

Source: Elaborated by the authors using data from CCMC (2000)

Figure 7. Vertical component of the plasma drift over a day. During daytime/nighttime period, the eastward/westward electric field causes upward/downward vertical plasma drift with a steep enhancement around dusk. This enhancement (highlighted in cyan)

is known as the prereversal enhancement of the vertical drift.

The PRE strongly influences the nighttime phenomenology over low latitudes, but it has a very complex configuration if a long spatial extent is considered (Sousasantos et al. 2018; 2020). It elevates the ionosphere to higher altitudes, where the neutral density decreases substantially. Thus, chemical recombination and the collision frequency are also reduced such that the geomagnetic field has a more decisive role in the plasma dynamics.

Moreover, in the early nighttime, the progressive absence of photoionization and ionization loss steepen the plasma bottom-side gradient upward. This steep gradient is opposite the gravity force (downward), and, under this configuration, the ionosphere is in an unstable equilibrium similar to the classical Rayleigh-Taylor instability description, first noticed by Dungey (1956). 
As previously mentioned, a force exerted over a plasma will give rise to a velocity, according to Eq. 6. When gravity is the force into consideration, $\boldsymbol{F}$ is written as $m \boldsymbol{g}$ in Eq. 6 . Since now the result depends on the charge, a gravity-driven current is established. Over the equatorial region, this current is eastward due to the orientations of $\boldsymbol{g}$ and $\boldsymbol{B}$.

If a seeding source disturbance is available in the early nighttime unstable scenario, an instability condition begins and may evolve progressively. It is widely accepted that gravity waves of tropospheric origin typically provide these seeding sources (e.g., Abdu et al. 2009b; Kelley et al. 1981; Kherani et al. 2009). Along the equatorial region, and specifically across the Brazilian territory, the intertropical convergence zone (ITCZ) is a system of wind circulation that seems to fit this description in creating troposphere-generated gravity waves (Röttger 1981). When these waves reach the F region bottom-side in the early nighttime scenario, the gravity-driven current encounters fluctuations in the plasma density. Consequently, polarization (eastward) electric fields are formed in the bottom-side of the ionospheric F region. Because of the geomagnetic field, these electric fields cause an upward drift of the low-density plasma, enhancing the local perturbation. This process may evolve up to a buoyant stage in which the low-density plasma from the bottom-side reaches the topside. This plasma density $(N)$ instability is known as generalized Rayleigh-Taylor instability, and its linear growth rate $(\gamma)$ under the action of the electric field and gravity may be expressed as:

$$
\gamma=L^{-I}\left(\frac{E}{B}+\frac{g}{v_{i n}}\right)
$$

where the bottom-side vertical $(h)$ gradient scale length is:

$$
L^{-1}=\left(\frac{1}{N}\right)\left(\frac{\partial N}{\partial h}\right)
$$

The electric field is the main driver to start and control instability development in the bottom-side, while gravity contributes to the buoyant rise up to the topside F region (Kelley et al. 1979b). As plasma depletions reach high altitudes, structures similar to bubbles are formed. These structures are commonly referred to as Equatorial Plasma Bubles (EPB). These events are closely related to aspects mentioned earlier in this work, namely solar activity, geomagnetic conditions, and seasonal period (Sobral et al. 2002). Equatorial plasma bubble dimensions typically are hundreds of kilometers both in zonal (Clemesha et al. 1964) and vertical directions (Woodman and La Hoz 1976). However, a cascading process during EPB evolution generates instabilities in progressively smaller sizes inside the structure, reaching meter scale (Haerendel 1973).

As EPBs rise over the equator, they propagate through the geomagnetic field lines and reach low-latitude regions. The level of depletion caused by these EPBs also varies depending on the background plasma density. Over the low-latitude region, this level of depletion is intensified because the background density was previously enhanced due to the fountain effect.

An example of an optical register of EPB structures as captured by an all-sky imager (6300 Å filter) is presented in Fig. 8 . The panels show a sequence of images in consecutive hours captured over the low-latitude station of Bom Jesus da Lapa, Brazil $\left(13^{\circ} 15^{\prime} \mathrm{S}, 43^{\circ} 25^{\prime} \mathrm{W}, \mathrm{LT} \sim \mathrm{UT}-3\right)$ during the night of December 14, 2020. The data may be accessed at INPE (2021). The green/ blue colors indicate larger/lesser concentrations of plasma $\left(\mathrm{O}^{+}\right)$, and the coverage of the image reaches a diameter of $\sim 1100 \mathrm{~km}$. In Fig. 8a (22:30 UT), the concentrated plasma in the lower boundary of the field of view (south) corresponds to the EIA southern crest (green). In the top (north), one can observe that EPB structures (darker blue) seem to be entering the field of view, penetrating southward (highlighted by the red arrows). In addition, these structures are drifting eastward, which also indicates the influence of a downward electric field (or, equivalently, an eastward thermospheric wind).

The subsequent panels of Fig. 8 (22:40-23:48 UT) show that the EPBs penetrate increasingly southern regions (highlighted by the red arrows). This movement is the equivalent to EPB ascension over the equatorial region, i.e., higher altitudes over the equator cause more southward extension in the north-south direction due to the geomagnetic-field-aligned propagation of the structures. As these depleted structures spread along the geomagnetic field lines, strong density gradients are formed, especially over the regions with more background plasma density, as in the EIA region. This is a critical parameter when considering transionospheric-propagating signals (Yeh and Liu 1982). 


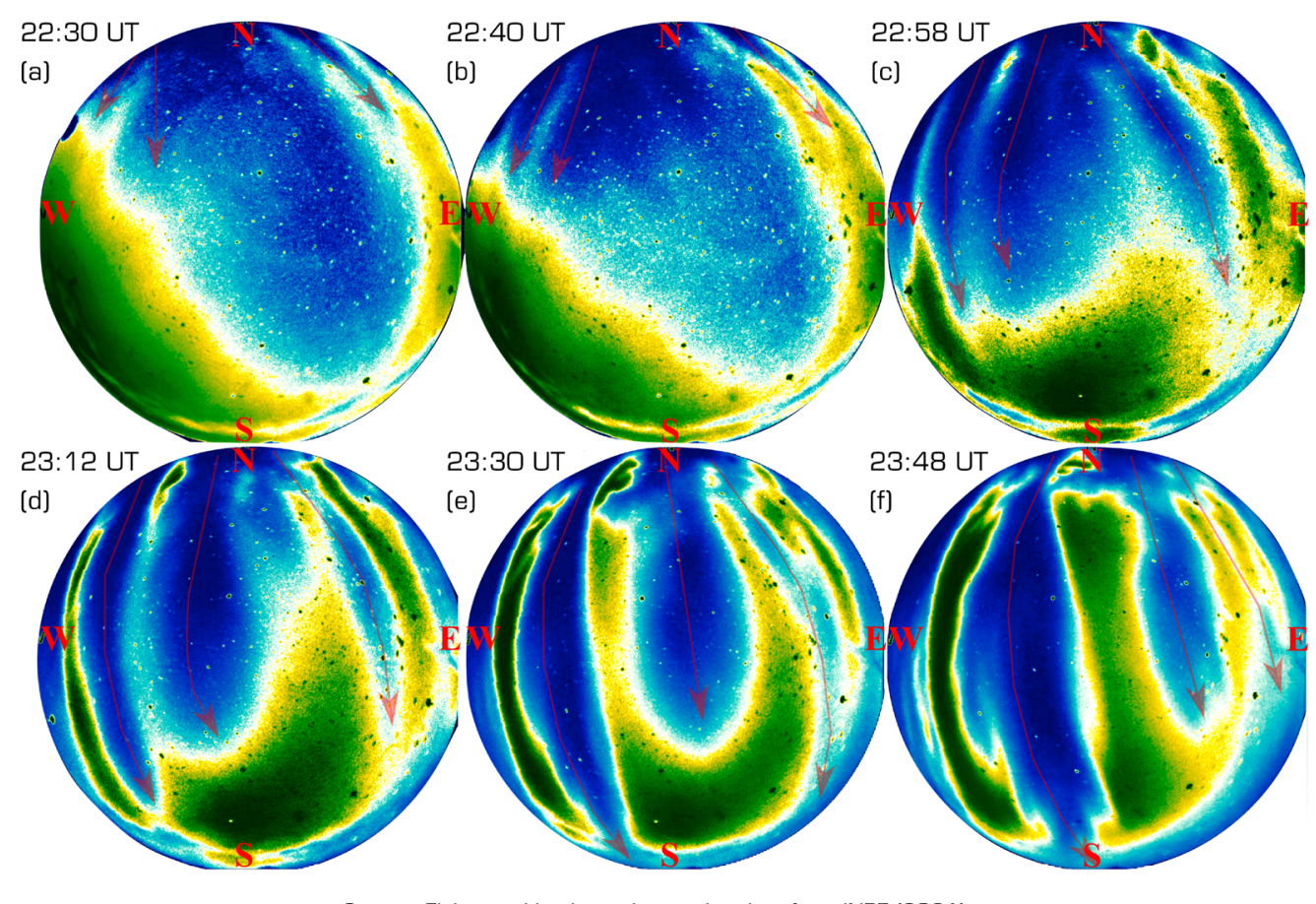

Source: Elaborated by the authors using data from INPE (2021).

Figure 8. Optical register of the development of EPB structures over Bom Jesus da Lapa, Brazil, captured by an all-sky imager (6300 Å filter). Green/blue regions indicate larger/lesser plasma concentrations, and red arrows indicate EPB penetrations. The EPB structures (dark blue) penetrate progressively southward, eventually reaching the region of the EIA and causing a significant level of depletion (or equivalently a large plasma density gradient).

As mentioned earlier, the EPB process is turbulent, producing a broad spectrum of instability ranges. Considering the GNSS L-band carrier frequencies, assuming an ionospheric pierce point (IPP) altitude of $350 \mathrm{~km}$ (IPP is the intersection between the signal path and an ionosphere modelled as a thin shell at a given height) and a zenith satellite elevation of $90^{\circ}$, density irregularities with scale sizes of approximately 365 to $423 \mathrm{~m}$ will cause severe amplitude fluctuations in the signals. These signals may also suffer phase shifts. When signals suffer such variations, this is commonly called ionospheric scintillation (Kintner et al. 2007; Yeh and Liu 1982). A widely used parameter for practical applications is the $S_{4}$ index, which measures amplitude scintillation. The $S_{4}$ index is defined as the normalized variance of the intensity $(I)$ of the signal over a period (typically 60 s), i.e.:

$$
S_{4}=\sqrt{\frac{\left\langle I^{2}\right\rangle-\langle I\rangle^{2}}{\langle I\rangle^{2}}}
$$

where $<>$ represents the average value for $60 \mathrm{~s}, I=A^{2}$, where $A$ is the amplitude of the signal.

To illustrate the relationship between EPB events and amplitude scintillation in the GNSS signals, data from a scintillation monitor deployed at Salvador station in Brazil ( $\left.13^{\circ} \mathrm{S}, 38^{\circ} 31^{\prime} \mathrm{W}, \mathrm{LT} \sim \mathrm{UT}-3\right)$ on the same night presented in Fig. 8 is exhibited in Fig. 9. This station is located at approximately the same geographic latitude as the all-sky imager station (Bom Jesus da Lapa) and is only $4.92^{\circ}$ eastward. Only data from satellites with elevation angles larger than $20^{\circ}$ were considered to avoid extensively long ray paths traversing the ionosphere.

The time when EPB structures of equatorial origin reach the field of view in the images in the panels of Fig. 8 is highlighted by a black dashed rectangle in Fig. 9.

In general, a level of $S_{4}$ larger than 0.2 is considered to be the minimum capable of degrading transionospheric signals (Kintner et al. 2007), making $S_{4}$ occurrences below this threshold negligible. As can be observed from Fig. 9, as soon as EPB structures reach the region covered by the all-sky imager ( 22:30 UT), the level of amplitude scintillation $\left(S_{4}\right)$ increases steeply, attaining large values 
corresponding to a scenario of severe scintillation and strong signal degradation. The $S_{4}$ remains large up to $\sim 04: 00 \mathrm{UT}$, fully agreeing with the EPB occurrence registered through the all-sky imager (not shown here). Therefore, for GNSS-based applications, EPB events like this one are significant adverse due to the scintillation and consequent severe signal degradation caused by these structures.

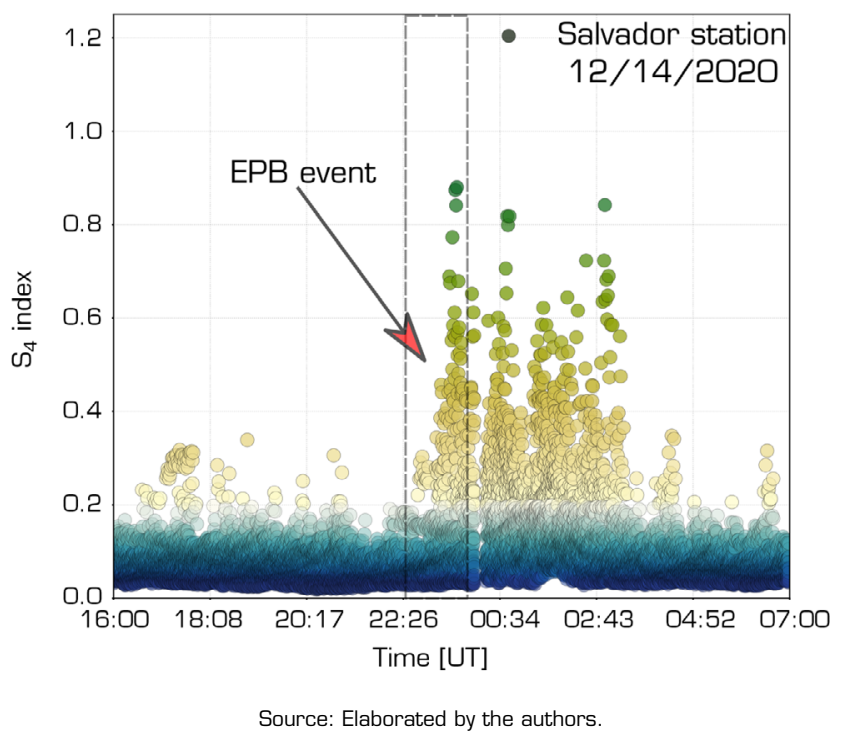

Figure 9. Amplitude scintillation $\left(S_{4}\right)$ registered at Salvador station, Brazil $\left(13^{\circ} \mathrm{S}, 38^{\circ} 31^{\prime} \mathrm{W}, \mathrm{LT} \sim \mathrm{UT}-3\right)$, close to Bom Jesus da Lapa, on the same night presented in Fig. 8. The scintillation index increases as soon as the EPB event reaches this region (black dashed rectangle) attaining large values.

\section{Consequences of EPBs for GNSS users and GBAS systems}

The discussion presented in the previous sections shows that space weather phenomenology over low latitudes often leads to the generation of EPBs, and these structures in turn can severely affect GNSS signals, including GBAS performance. Figures 10 and 11 display examples of the effects of EPBs on GBAS operation. The three panels of Fig. 10 illustrate the flow of events resulting from EPB phenomena over low-latitude regions at the night between November 21 and 22, 2014. The Fig. 10a shows a total electron content (TEC) map representing the spatial distribution (longitude and latitude) of ionospheric plasma over the Brazilian region at 21:25 local time. The regions with more significant TEC concentrations (in red) are the EIAs, as indicated in Fig. 6. Equatorial plasma bubble structures are the north-south depleted regions (elongated streaks) and are identified by light blue arrows. The solid red line corresponds to the geomagnetic equator, and the white thicker dashed line in the southeastern region highlights bounds where spatial changes (gradients) of at least 10 TECs over a few hundreds of km were observed. The white thicker dashed line surrounds the São José dos Campos (green dot) station, indicating the presence of significant TEC gradients due to EPB equatorial/ meridional development as EPBs propagate across the EIA region during this night. The location of the Rio de Janeiro International Airport is also shown (magenta dot) in order to convey the significance of these results (Fig. 11). For more details regarding TEC definitions, map construction, validation and use of TEC maps, please refer to Oliveira et al. (2020) and Marini-Pereira et al. (2020).

The Fig. 10b shows the temporal profile of the $S_{4}$ index over this night. A receiver deployed at São José dos Campos, close to the EIA region, provided this data. In the early nighttime, the data exhibits noticeable scintillation activity $\left(S_{4}>0.4\right.$ is typically assumed to be a considerable event), suggesting that multiple satellite links were affected by EPBs. According to Moraes et al. (2014), the tracking error variance $\sigma_{\phi S}^{2}$ of the GPS carrier tracking loop is expressed by:

$$
\sigma_{\phi \varepsilon}^{2}=\sigma_{\phi S}^{2}+\sigma_{\phi T}^{2}+\sigma_{\phi o s c}^{2}+2 \rho \sigma_{\phi S} \sigma_{\phi T}
$$

where $\sigma_{\phi S}^{2}$ is the phase scintillation error component, $\sigma_{\phi T}^{2}$ is the thermal noise component, which is directly influenced by the scintillation amplitude, and $\sigma_{\phi \mathrm{OSC}}^{2}$ is related to the receiver oscillator noise. Because amplitude and phase scintillation are correlated events, the $\rho$ 
parameter is the correlation coefficient between errors due to amplitude and phase scintillation. According to Humphreys et al. (2010), for a receiver with $\sigma_{\phi S}^{2}<14.3^{\circ}$, the tracking loop operates in a linear regime. When this threshold is exceeded, the receiver loses phase lock and cannot demodulate GNSS navigation data or provide reliable observables. Loss of lock events are more likely to happen as $S_{4}$ increases, i.e., during more severe ionospheric scintillation scenarios. Vani et al. (2021) showed that, under a strong scintillation scenario, there is a probability of roughly $4 \%$ that at least three satellites will be affected simultaneously. Multiple-channel degradation of this sort is even worse for GNSS-dependent applications, as it is more likely to cause unavailability and impaired position estimation.

Another aspect of performance degradation during scintillation is what is known as a "cycle slip". In a cycle slip event, the phase tracking loop jumps from one integer (or half-integer) level to another on one or more signals, causing the standard deviation of receiver phase error to increase. Errors of this nature sometimes are not immediately noticed, leading to accumulated errors or momentary unavailability of GPS carrier-phase observables. Humphreys et al. (2010) established a relationship between the bit error probability for binary differential phase-shift keying (DPSK) and the occurrence of cycle slips for a GPS receiver under scintillation effects. Later, Moraes et al. (2018) used fading coefficients (a statistical property of scintillation) to show that aspects of signal propagation orientation about EPBs may result in more cycle slips. Recently, Portella et al. (2021) showed, through simulations, that amplitude fading events deeper than $-15 \mathrm{~dB}$ are critical for the receiver operation due to the high probability of cycle slips. Therefore, strong scintillation occurrences, such as the event shown shown in Fig10b, are likely to limit the availability of the GPS receiver in terms of producing high-quality range measurements to all satellites in view, which is very important to GBAS and other precise GNSS operations.
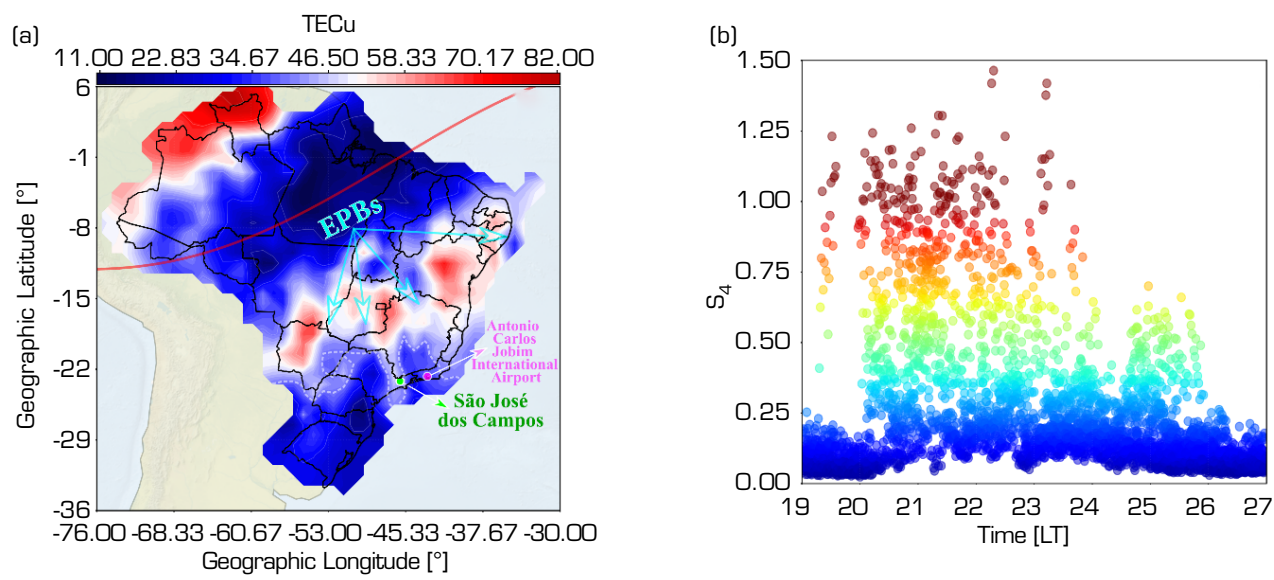

(c)

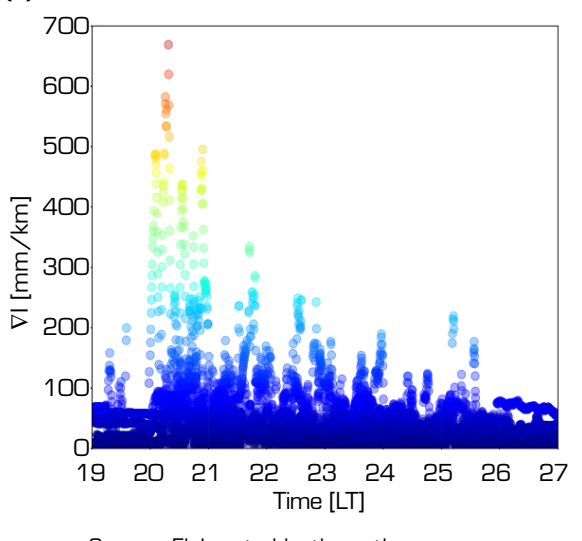

Source: Elaborated by the authors.

Figure 10. Illustration of EPB events and their consequences for GBAS users. (a) TEC distribution over Brazilian territory exhibiting multiple EPBs (depletions) extending from equatorial to low-latitude region along geomagnetic field lines. (b) amplitude scintillation index $\left(S_{4}\right)$ registered by the São José dos Campos station during the EPB events. (c) large ionospheric gradients $|\nabla I|$ formed due to EPB propagation across the EIA region. The calculation used the station-pair method based upon measurements from two ground stations in São José dos Campos. 
Figure 10c shows the ionospheric spatial gradients calculated using the station-pair method (Datta-Barua et al. 2010) using measurements from two ground stations $10.22 \mathrm{~km}$ apart and deployed at São José dos Campos, Brazil. In this panel, slant ionospheric gradients, $|\nabla I|$, reach values much larger than $400 \mathrm{~mm} \cdot \mathrm{km}^{-1}$, which is the upper limit of the conterminous United States (CONUS) ionospheric threat model for GBAS. While existing GBAS is designed to mitigate gradients within this threat model, gradients significantly exceeding this model potentially threaten the integrity of GBAS, or if GBAS is redesigned to also mitigate these more extreme events, its availability for precision approach operations would be significantly degraded (Yoon et al. 2019).

Figure 11 exhibits the effects on GBAS accuracy determined by an independent ground monitor station (at a known, presurveyed location) under a strong ionospheric gradient scenario similar to that presented in Fig. 10. This dataset was obtained at the Rio de Janeiro International Airport (magenta dot in Fig. 10) for the night between November 18 and 19, 2011. While it does not belong to the same night of the EPB event shown in the previous figure, it depicts the entire chain of EPB effects, from plasma instability processes in the equatorial and low-latitude nighttime ionosphere up to fading and disruption of transionospheric signals affecting GBAS and other GNSS users.

(a)

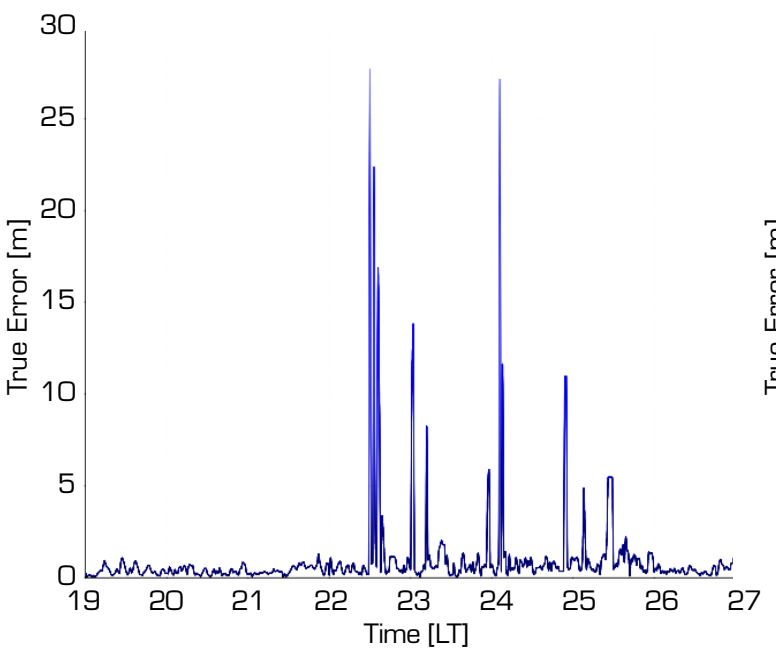

(b)

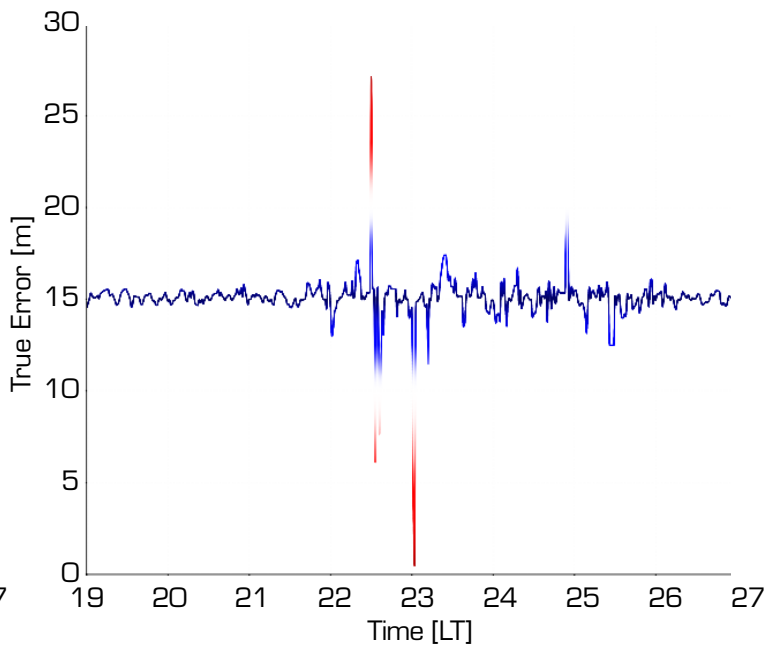

Source: Elaborated by the authors.

Figure 11. Example of GBAS errors measured by an independent ground receiver under a severe $\mathrm{EPB} /$ ionospheric gradient scenario. The dataset was obtained at the Rio de Janeiro International Airport in 2011. (a) Horizontal error (in meters). (b) Vertical error (in meters).

Figure 11 shows the actual horizontal/vertical errors at the independent ground monitor station after applying corrections provided by the nearby GBAS. A color scheme is used along the curves as a tool to visualize when certain critical error levels were reached. The blue color, from darker to lighter, corresponds to true error magnitudes below 40 and $10 \mathrm{~m}$ for horizontal and vertical components. Colors from white to red represent values with magnitudes larger than 40 and $10 \mathrm{~m}$ for the horizontal and vertical components, which are beyond the alert limits stablished for category I operations at the minimum decision height of $200 \mathrm{ft}$. At certain times, the error increases substantially above typical values of less than $1 \mathrm{~m}$ and eventually breaches the tightest vertical alert limits for category I (CAT I) operations.

The results presented in Figs. 10 and 11 indicate that EPBs may damage GNSS performance in at least two ways: through scintillation, due to the cascading process throughout the turbulent development of the instability, or as a result of the large spatial plasma gradients, which are notably enhanced when EPB depletions reach the EIA region. Both of these usually occur when EPBs are present. 


\section{FINAL REMARKS}

This article is the second of a two-part series of survey papers that provide an overview of GBAS technology and the main challenges to GBAS operation in low-latitude regions, specifically in Brazil. Due to the strong influence of the ionosphere on GNSS signals, space physics concepts underlying ionospheric behavior were discussed in this part two of this series.

The content presented in this paper is designed to demonstrate the connections between solar activity, geomagnetic configuration, and ionospheric electrodynamics. The relationships between solar activity, the geomagnetic conditions and the geometry of the geomagnetic field, neutral winds, electric fields and currents, ionospheric background plasma density, plasma drifts, and the instability development make up the framework of the space weather phenomena that affect GNSS applications. The prominent phenomenon of interest are EPBs structures due to their marked impact on GNSS signals in low-latitude regions. When this chain of interrelated physical events leads to EPB formation, GNSS and GNSS augmentation systems such as GBAS may be severely affected. Therefore, applications of GNSS in low-latitude regions must consider these physical aspects and the consequences they can lead to.

Understanding the main aspects described in this paper provides an improved perspective of the challenges involved in operating a safety-critical GNSS-based system for air navigation applications in the low-latitude ionospheric environment. This knowledge is important for service providers and operators of GNSS-based systems in low latitudes. Further understanding of space weather behavior, observance and warning of EPB formation and propagation in near-real-time, and modernization of GNSS and its augmentations will contribute to improving availability and integrity for GNSS-dependent users in these regions over the next couple of decades.

\section{AUTHORS' CONTRIBUTION}

Conceptualization: Moraes AO, Marini-Pereira L Sousasantos J and Pullen S; Investigation: Sousasantos J and MariniPereira L; Methodology: Sousasantos J; Marini-Pereira L and Moraes AO; Resources: Sousasantos J; Writing - original draft: Sousasantos J and Marini-Pereira L; Writing - review \& editing: Moraes AO and Pullen S.

\section{DATA AVAILABILITY STATEMENT}

The dataset used in Figures 1 and 3 may be accessed at: https://omniweb.gsfc.nasa.gov/form/dx1.html.

The dataset used in Figure 4 may be accessed at: https://www.ngdc.noaa.gov/IAGA/vmod/igrf.html.

The dataset used in Figures 5 and 7 may be accessed at: https://ccmc.gsfc.nasa.gov/modelweb/models/iri2016_vitmo.php.

The dataset used in Figure 6 may be accessed at: https://doi.org/10.5281/zenodo.5657807

The dataset used in Figure 8 may be accessed at: http://www2.inpe.br/climaespacial/portal/en/.

The dataset used in Figure 9 may be accessed at: https://ismrquerytool.fct.unesp.br/is/.

The dataset used in Figure 10 may be accessed at: http://www2.inpe.br/climaespacial/portal/en/; https://ismrquerytool.fct. unesp.br/is/ and https://doi.org/10.5281/zenodo.5657807.

\section{FUNDING}

Fundação de Amparo à Pesquisa do Estado de São Paulo

[https://doi.org/10.13039/501100001807]

Grants Nos: 2018/06158-9 and 2016/24970-7 
Conselho Nacional de Desenvolvimento Científico e Tecnológico

[https://doi.org/10.13039/501100003593]

Grants Nos: 314043/2018-7 and 465648/2014-2

\section{ACKNOWLEDGEMENTS}

Jonas Sousasantos acknowledges FAPESP for supporting his reasearch. Leonardo Marini-Pereira is grateful to the Departamento de Controle do Espaço Aéreo (DECEA) and the Instituto de Controle do Espaço Aéreo (ICEA) for supporting his doctoral research. The authors acknowledge EMBRACE (Estudo e Monitoramento Brasileiro do Clima Espacial) for the all-sky data (http:// www2.inpe.br/climaespacial/portal/en/). The OMNI data were obtained from the GSFC/SPDF OMNIWeb interface at https:// omniweb.gsfc.nasa.gov, the authors thank all the staff involved. We also acknowledge Dr. D. Bilitza, all the members of the IRI working group, and NASA's Space Physics Data Facility (SPDF) and Community Coordinated Modeling Center (CCMC) for the IRIweb online computation service. This work uses SAMI2 model, the authors are grateful to Dr. Joseph D. Huba and NRL for SAMI2 distribution. The authors acknowledge the Instituto Brasileiro de Geografia e Estatística (IBGE) for providing GNSS data from the RBMC network, used for TEC estimation. The scintillation monitoring stations deployed in the context of Projects CIGALA/CALIBRA were funded by the European Commission (EC) in the framework of awards FP7-GALILEO-2009-GSA and FP7-GALILEO-2011-GSA-1a, as well of FAPESP award 06/04008-2, 2017/50115-0, CNPq (465648/2014-2) and the data can be accessed at http://ismrquerytool. fct.unesp.br/is/ using ISMR Query Tools. We also acknowledge all the staff involved in the development and distribution of the International Geomagnetic Reference Field (IGRF).

\section{REFERENCES}

[CCMC] Community Coordinated Modeling Center (2000) International Reference Ionosphere - IRI (2016) with IGRF-13 coefficients. CCMC. [accessed May 2 2021]. https://ccmc.gsfc.nasa.gov/modelweb/models/iri2016_vitmo.php

[IAGA] International Association of Geomagnetism and Aeronomy (2019) International Geomagnetic Reference Field. IAGA. [accessed Apr 20 2021]. https://www.ngdc.noaa.gov/IAGA/vmod/igrf.html

[ICAO] International Civil Aviation Organization (2019) Doc 10100, Manual on space weather information in support of international air navigation. Montreal: ICAO.

[INPE] Instituto Nacional de Pesquisas Espaciais (2021) Embrace: Estudo e Monitoramento Brasileiro do Clima Espacial. INPE. [accessed May 15 2021]. http://www2.inpe.br/climaespacial/portal/en/

[NASA] National Aeronautics and Space Administration (2004) OMNIWeb: Interface to produce plots, listings or output files from OMNI 2. NASA. [accessed May 16 2021]. https://omniweb.gsfc.nasa.gov/form/dx1.html

Abdu MA, Bittencourt JA, Batista IS (1981) Magnetic declination control of the equatorial F region dynamo electric field development and spread F. J Geophys Res 86(A13):11443-11446. https://doi.org/10.1029/JA086iA13p11443

Abdu MA, Sobral JHA, Nelson OR, Batista IS (1985) Solar cycle related range type spread- $F$ occurrence characteristics over equatorial and low latitude stations in Brazil. J Atmos Terr Phys 47(8-10):901-905. https://doi.org/10.1016/00219169(85)90065-0

Abdu MA, Batista IS, Sobral JHA (1992) A new aspect of magnetic declination control of equatorial spread $\mathrm{F}$ and $\mathrm{F}$ region dynamo. J Geophys Res Space Phys 97(A10):14897-14904. https://doi.org/10.1029/92JA00826 
Abdu MA, Maruyama T, Batista IS, Saito S, Nakamura M (2007) Ionospheric responses to the October 2003 superstorm: Longitude/local time effects over equatorial low and middle latitudes. J Geophys Res Space Phys 112(A10). https://doi. org/10.1029/2006JA012228

Abdu MA, Kherani EA, Batista IS, Sobral JHA (2009a) Equatorial evening prereversal vertical drift and spread F suppression by disturbance penetration electric fields. Geophys Res Lett 36(19). https://doi.org/10.1029/2009GL039919

Abdu MA, Kherani EA, Batista IS, Paula ER, Fritts DC, Sobral JHA (2009b) Gravity wave initiation of equatorial spread F/ plasma bubble irregularities based on observational data from the SpreadFEx campaign. Ann Geophys 27:2607-2622. https:// doi.org/10.5194/angeo-27-2607-2009

Abdu MA, Batista IS, Bertoni F, Reinisch BW, Kherani EA, Sobral JHA (2012) Equatorial ionosphere responses to two magnetic storms of moderate intensity from conjugate point observations in Brazil. J Geophys Res Space Phys 117(A5). https://doi.org/10.1029/2011JA017174

Abdu MA (2016) Electrodynamics of ionospheric weather over low latitudes. Geosci Lett 3:11. https://doi.org/10.1186/ s40562-016-0043-6

Alfvén H (1958) On the theory of magnetic storms and aurorae. Tellus 10(1):104-116. https://doi.org/10.3402/tellusa. v10i1.9213

Anderson DN (1973) A theoretical study of the ionospheric F region equatorial anomaly-I. Theory. Planet Space Sci 21(3):409-419. https://doi.org/10.1016/0032-0633(73)90040-8

Bartels J (1938) Potsdamer erdmagnetische Kennziffern: 1 Mitteilung. Zeitschrift für Geophysik 14(68-78):699-718.

Bartels J, Heck NH, Johnston HF (1939) The three-hour-range index measuring geomagnetic activity. Terr Magn Atmos Electr 44(4):411-454. https://doi.org/10.1029/TE044i004p00411

Bilitza D, Altadill D, Truhlik V, Shubin V, Galkin I, Reinisch B, Huang X (2017) International reference ionosphere 2016: From ionospheric climate to real-time weather predictions. Space Weather 15:418-429. https://doi.org/10.1002/2016SW001593

Blanc M, Richmond AD (1980) The ionospheric disturbance dynamo. J Geophys Res Space Phys 85(A4):1669-1686. https:// doi.org/10.1029/JA085iA04p01669

Clemesha BR (1964) An investigation of the irregularities in the F-region associated with equatorial type spread-F. J Atmos Terr Phys 26(1):91-112. https://doi.org/10.1016/0021-9169(64)90111-4

Datta-Barua S, Lee J, Pullen S, Luo M, Ene A, Qiu D, Zhang G, Enge P (2010) Ionospheric threat parameterization for local area global-positioning-system-based aircraft landing systems. J Aircr 47(4):1141-1151. https://doi.org/10.2514/1.46719

Davis TN, Sugiura M (1966) Auroral electrojet activity index $A E$ and its universal time variations. J Geophys Res 71(3):785801. https://doi.org/10.1029/JZ071i003p00785

Dungey JW (1956) Convective diffusion in the equatorial $F$ region. J Atmos Terr Phys 9(5-6):304-310. https://doi. org/10.1016/0021-9169(56)90148-9

Farley DT, Bonelli E, Fejer BG, Larsen MF (1986) The prereversal enhancement of the zonal electric field in the equatorial ionosphere. J Geophys Res Space Phys 91(A12):13723-13728. https://doi.org/10.1029/JA091iA12p13723

Feess WA, Stephens SG (1987) Evaluation of GPS ionospheric time-delay model. IEEE Trans Aerosp Electron Syst AES23(3):332-338. https://doi.org/10.1109/TAES.1987.310830

Fejer BG, Navarro LA, Sazykin S, Newheart A, Milla MA, Condor P (2021) Prompt penetration and substorm effects over 
Jicamarca during the September 2017 geomagnetic storm. J Geophys Res Space Phys 126(8):e2021JA029651. https://doi. org/10.1029/2021JA029651

Haerendel G (1973) Theory of equatorial spread-F. Garching: Max-Planck Institute für Physik und Astrophysik. Preprint.

Hanson WB, Moffet RJ (1966) Ionization transport effects in the equatorial F-region ionosphere. J Geophys Res 71(23):55595572. https://doi.org/10.1029/JZ071i023p05559

Huba JD, Joyce G, Fedder JA (2000) Sami2 is another model of the ionosphere (SAMI2): A new low-latitude ionosphere model. J Geophys Res Space Phys 105(A10):23035-23053. https://doi.org/10.1029/2000JA000035

Humphreys TE, Psiaki ML, Kintner PM (2010) Modeling the effects of ionospheric scintillation on GPS carrier phase tracking. IEEE Trans Aerosp Electron Syst 46(4):1624-1637. https://doi.org/10.1109/TAES.2010.5595583

Johnson CY (1969) Ion and neutral composition of the ionosphere. Ann IQSY 5:197-2013.

Kelley MC, Fejer BG, Gonzales CA (1979a) An explanation for anomalous ionospheric electric fields associated with a northward turning of the interplanetary magnetic field. Geophys Res Lett 6(4):301-304. https://doi.org/10.1029/ GL006i004p00301

Kelley MC, Baker KD, Ulwick JC (1979b) Late time barium cloud striations and their possible relationship to equatorial spread F. J Geophys Res Space Phys 84(A5):1898-1904. https://doi.org/10.1029/JA084iA05p01898

Kelley MC, Larsen MF, LaHoz C, McClure JP (1981) Gravity wave initiation of equatorial spread F: A case study. J Geophys Res Space Phys 86(A11):9087-9100. https://doi.org/10.1029/JA086iA11p09087

Kherani EA, Abdu, MA, Paula ER, Fritts DC, Sobral JHA, Meneses Junior FC (2009) The impact of gravity waves rising from convection in the lower atmosphere on the generation and nonlinear evolution of equatorial bubble. Ann Geophy 27(4):1657-1668. https://doi.org/10.5194/angeo-27-1657-2009

Kikuchi T, Hashimoto KK, Nozaki K (2008) Penetration of magnetospheric electric fields to the equator during a geomagnetic storm. J Geophys Res Space Phys 113(A6). https://doi.org/10.1029/2007JA012628

King JW (1968) Airglow observations and the decay of the ionospheric equatorial anomaly. J Atmos Terr Phys 30(3):391-402. https://doi.org/10.1016/0021-9169(68)90110-4

Kintner PM, Ledvina BM, Paula ER (2007) GPS and ionospheric scintillations. Space Weather 5(9). https://doi. org/10.1029/2006SW000260

Klobuchar JA (1987) Ionospheric time-delay algorithm for single-frequency GPS users. IEEE Trans Aerosp Electron Syst AES-23(3):325-331. https://doi.org/10.1109/TAES.1987.310829

Knecht RW, Davies K (1961) Solar flare effects in the F region of the ionosphere. Nature 190:797-778. https://doi. $\operatorname{org} / 10.1038 / 190797 \mathrm{a} 0$

Loewe CA, Prölss GW (1997) Classification and mean behavior of magnetic storms. J Geophys Res 102(A7):14209-14213. https://doi.org/10.1029/96JA04020

Marini-Pereira L, Lourenço LFD, Sousasantos J, Moraes AO, Pullen S (2020) Regional ionospheric delay mapping for lowlatitude environments. Radio Science, 55(12):e2020RS007158. https://doi.org/10.1029/2020RS007158

Moraes AO, Costa E, Paula ER, Perrella WJ, Monico JFG (2014) Extended ionospheric amplitude scintillation model for GPS receivers. Radio Sci 49(5):315-329. https://doi.org/10.1002/2013RS005307 
Moraes AO, Vani BC, Costa E, Abdu MA, Paula ER, Sousasantos J, Monico JFG, Forte B, Negreti PMS, Shimabukuro MH (2018) GPS availability and positioning issues when the signal paths are aligned with ionospheric plasma bubbles. GPS Solut 22:95. https://doi.org/10.1007/s10291-018-0760-8

Oliveira CBA, Espejo TMS, Moraes AO, Costa E, Sousasantos J, Lourenço LFD, Abdu MA (2020) Analysis of plasma bubble signatures in total electron content maps of the low-latitude ionosphere: A simplified methodology. Surv Geophys 41:897931. https://doi.org/10.1007/s10712-020-09584-7

Parker EN (1957a) Newtonian development of the dynamical properties of ionized gases of low density. Phys Rev 107:924. https://doi.org/10.1103/PhysRev.107.924

Parker EN (1957b) Sweet's mechanism for merging magnetic fields in conducting fluids. J Geophys Res 62(4):509-520. https://doi.org/10.1029/JZ062i004p00509

Parker EN (1958) Interaction of the solar wind with the geomagnetic field. Phys Fluids 1:171. https://doi.org/10.1063/1.1724339

Peymirat C, Richmond AD, Kobea AT (2000) Electrodynamic coupling of high and low latitudes: Simulations of shielding/ overshielding effects. J Geophys Res 105(A10):22991-23003. https://doi.org/10.1029/2000JA000057

Portella IP, Moraes AO, da Silva Pinho M, Sousasantos J, Rodrigues F (2021) Examining the tolerance of GNSS receiver phase tracking loop under the effects of severe ionospheric scintillation conditions based on its bandwidth. Radio Sci 56(6): e2020RS007160. https://doi.org/10.1029/2020RS007160

Prölss GW (2011) Density perturbations in the upper atmosphere caused by the dissipation of solar wind energy. Surv Geophys 32:101-195. https://doi.org/10.1007/s10712-010-9104-0

Rishbeth H, Garriott OK (1969) Introduction to ionospheric physics. New York: Academic Press.

Röttger J (1981) Equatorial spread-F by electric fields and atmospheric gravity waves generated by thunderstorms. J Atmos Terr Phys 43(5-6):453-462. https://doi.org/10.1016/0021-9169(81)90108-2

Sahai Y, Fagundes PR, Bittencourt JA (1999) Solar cycle effects on large scale equatorial F-region plasma depletions. Adv Space Res 24(11):1477-1480. https://doi.org/10.1016/S0273-1177(99)00709-7

Sobral JHA, Abdu MA, Takahashi H, Taylor MJ, Paula ER, Zamlutti CJ, Aquino MG, Borba GL (2002) Ionospheric plasma bubble climatology over Brazil based on 22 years (1977-1998) of 630nm airglow observations. J Atmos Sol Terr Phys 64(1214):1517-1524. https://doi.org/10.1016/\$1364-6826(02)00089-5

Sousasantos J, Moraes AO, Sobral JHA, Muella MTAH, Paula ER, Paolini RS (2018) Climatology of the scintillation onset over southern Brazil. Ann Geophy 36(2):565-576. https://doi.org/10.5194/angeo-36-565-2018

Sousasantos J, Abdu MA, Santos A, Batista I, Silva A, Loures LE (2020) Further complexities on the pre-reversal vertical drift modeling over the Brazilian region: a comparison between long-term observations and model results. J Space Weather Space Clim 10:20. https://doi.org/10.1051/swsc/2020022

Sugiura M (1964) Hourly values of equatorial Dst for the IGY. Ann Int Geophys Yr 35(Part 1):9-45.

Sugiura M, Kamei T (1991) Equatorial Dst index: 1957-1986 (IAGA Bulletin nº 40). Saint-Maur-Des-Fosses: ISGI Publications Office. [accessed April 5 2021]. http://solar.gmu.edu/meetings/cdaw/data/cdaw4/McPherron/References/SugiuraKamei_ Dst_Derivation.pdf

Tan Y, Hu Q, Wang Z, Zhong Q (2018) Geomagnetic index Kp forecasting with LSTM. Space Weather 16(4):406-416. https:// doi.org/10.1002/2017SW001764 
Tsurutani BT, Verkhoglyadova OP, Mannucci AJ, Lakhina GS, Li G, Zank GP (2009) A brief review of 'solar flare effects' on the ionosphere. Radio Science 44(1), RS0A17. https://doi.org/10.1029/2008RS004029

Vani BC, Moraes AO, Salles LA, Breder VHF, Freitas MJS, Monico JFG, Paula ER (2021) Monitoring ionospheric scintillations with GNSS in South America: Scope, results, and challenges. In Petropoulos GP, Srivastava PK, editors. GPS and GNSS Technology in Geosciences. Amsterdam: Elsevier. p. 255-280. https://doi.org/10.1016/B978-0-12-818617-6.00012-3

Woodman RF, La Hoz C (1976) Radar observations of $F$ region equatorial irregularities. J Geophys Res 81(31):5447-5466. https://doi.org/10.1029/JA081i031p05447

Yeh KC, Liu C-H (1982) Radio wave scintillations in the ionosphere. Proc IEEE 70(4):324-360. https://doi.org/10.1109/ PROC.1982.12313/

Yoon M, Kim D, Pullen S, Lee J (2019) Assessment and mitigation of equatorial plasma bubble impacts on category I GBAS operations in the Brazilian region. Navigation 66(3):643-659. https://doi.org/10.1002/navi.328 